\title{
International Maritime Health Association (IMHA) - expanding participation, coverage and service
}

\author{
Jørgen Riis Jepsen ${ }^{1}$, Luisa Canals ${ }^{2}$, Arne Ulven ${ }^{3}$, David Lucas ${ }^{4}$ \\ ${ }^{1}$ Centre of Maritime Health and Society, University of Southern Denmark, Esbjerg, Denmark \\ 2IMHA Research Group Chair, SEMM, Postgraduate Maritime Health Courses in Cadiz University, Tarragona, Spain \\ ${ }^{3}$ Norwegian Centre for Maritime Medicine, Bergen, Norway \\ ${ }^{4}$ Université de Bretagne Occidentale, Brest, France
}

With a background as an international scientific society linked to national societies of maritime medicine, International Maritime Health Association (IMHA) has mainly addressed issues of a medical character that relate to seafarers and fishermen and to some extent also to offshore and port workers.

Major topics dealt with by IMHA through the years include the challenges relating to health examinations of workers at sea, and the occurrence and management of medical emergencies in case of accidents and diseases on board. These medical topics still remain core issues in maritime medicine - in particular with regard to their contribution to health and safety of seafarers. Consequently, it is important for IMHA to continue to deal with such medical themes.

Six major thematic research areas have been recently identified. In addition to healthcare access, delivery and integration, and telehealth, issues such as non-communicable diseases and physical health problems, communicable diseases, psychological functioning and health, and safety-related issues are suggested key areas for future attention and research. Broader applied research methodologies should include randomised controlled trials, longitudinal studies as well as more qualitative research [1].

IMHA has addressed additional and important aspects of maritime health and safety. Common to many of these aspects, however, is that they require skills from other disciplines than maritime and occupational medicine. Contribution from researchers and practitioners in other medical as well as non-medical specialties is needed. Optimizing safe shipping and technical prevention on board, for example, would benefit from including the technical skills and expertise possessed by maritime deck and machine officers. Improved psychosocial climate on board and promotion of the "happy ship" would require further psychological expertise. Likewise, IMHA and the maritime communities would greatly benefit from research contributions from sociology, law, public health, economics, etc. An interdisciplinary approach is of utmost importance for the further development of maritime health, safety and environment.

Researchers and practitioners who can look at maritime health and safety from new angles have already contributed to a better understanding of the challenges and proposed better solutions to them than what could be achieved by strictly medical inputs. There is already a trend that researchers from other scientific fields than medicine participate actively in the scientific events organised by IMHA, such as the International Symposia of Maritime Health (ISMH) that take place every 2 years. Still, there is a potential that researchers and practitioners in non-medical fields can contribute further to our aims, and at the same time benefit from the platform for maritime health and safety research provided by IMHA. Many universities and maritime training institutions share our ambitions, and the same can be said about national and international maritime authorities, and, e.g. shipping organisations, unions etc. in a global context. All these reasons have justified the creation inside IMHA of the IMHA Research Group. As stated in the IMHA Newsletter [2] the aims of IMHA Research Group are to facilitate research, to create research networks and to disseminate the evidence in maritime health. Training and continuing education of maritime health staff and studying and promoting competences in maritime medicine are other main objectives.

Another issue is the fact that maritime health and safety research tends to be concentrated in specific parts of the world - in particular Europe, North America, and Australia. Major seafaring countries are largely unrepresented with regard to such research as well as in the activities of IMHA. In addition, although the vast majority of the world's seafarers and fishermen come from other parts of the world, 
notably Asia, but also Latin America and Africa, there is only little research that IMHA have access to, and which addresses the health and safety of their fishermen and of their seafarers in the merchant fleets, even when they work on internationally flagged vessels [1, 3].

We know that there are many potential IMHA-contributors from all continents in the medical field and in other areas of maritime research. In fact, many universities and other research institutions, hospitals, maritime academies, scientific societies, maritime health services, maritime authorities, etc., in many parts of the world have never heard about IMHA, and IMHA may not be aware of their existence. This situation occurs in spite of the fact that many of them are already important stakeholders, who produce maritime health and safety research or apply such research in practice. There may well be much research conducted already, which is published in a language that is not known by non-nationals. This research is likely to be unknown by the scientific community on a global scale and would benefit by being translated and disseminated into the English language. The researchers and practitioners from these institutions could benefit from IMHA memberships - individual or corporate, by enjoying the scientific fora such as the ISMH symposia and other scientific meetings arranged by IMHA, by joining the facilities of IMHA Research Group and by publishing in the 'International Maritime Health' journal, which is now the official journal of IMHA. To spread the knowledge on maritime health geographically and by languages, the IMHA Research Group has decided to start with three subgroups by localisation and communication by families of languages that have taken maritime names: Mediterranean, Atlantic, Pacific [2]. The latest activities planned and already executed have had an impact in geographical areas that need more attention. In Africa, the IMHA Research Group chair has helped in the organisation of first scientific meeting of the Morocco National Society of Maritime Medicine (SMMM, Tangiers, 20 December 2014), and the IMHA President was present in the 9ème Congrès International Hispano-francophone de Médecine Maritime, Agadir, 15 October 2015. A collaborative meeting with VININAM is planned in Haiphong by March $25-27^{\text {th }}, 2016$. An IMHA workshop about MLC and an IMHA Latina Seminar will be held in Panama, June $6-8^{\text {th }}, 2016$. The next $14^{\text {th }}$ ISMH will take place in Asia, Manila, March 21-24 ${ }^{\text {th }}, 2017$ ("Emerging Concepts in Maritime Medicine"). Worldwide resources like online-based postgraduate, expert and master courses are organised in Spanish and English versions [4-6].

There is an increasing awareness arising that research in maritime health and safety should aim to be conducted in an interdisciplinary manner. This can be achieved by promoting participation from researchers in other fields than medicine. It is also clear that a more global involvement would contribute significantly to our knowledge base, not least through further cooperation with researchers, practitioners, and other stakeholders in the emerging economies and developing countries. We should therefore do our best to promote both.

Bringing together Nordic maritime health and safety researchers from all fields of science has already broadened the scope of their research. Until now, Nordic meetings every second year have taken place in Esbjerg, Gothenburg and Bergen, respectively. These meetings have demonstrated that researches with different backgrounds can favour by being brought together for interdisciplinary presentations and discussions. New friendships and collaboration have developed during these meetings and provided the participants with mutual knowledge about the Nordic research institutions, their active researchers and scientific interests, and ongoing and planned projects. This information has promoted networking and resulted in shared Nordic projects.

Based on the experiences from the Nordic meetings it is proposed that IMHA pursues similar goals on a global scale. Previous to the $13^{\text {th }}$ ISMH in Bergen, 23 June 2015, there was a joint meeting between IMHA Research Group and Nordic researchers aiming to disseminate knowledge, share experiences and start collaboration. These contacts during the Symposium have resulted in collaboration among IMHA members, in this case between IMHA Research Group and the Telemedicine Research Group. One of the consequences was the arrangement together with a meeting in Rome, October 30-31 ${ }^{\text {st }}, 2015$ in collaboration with Centro Internazionale Radio Medico that has generated research papers to be published in the 'International Maritime Health' journal.

A further extension of the scopes of research would be beneficial for IMHA and at the same time be useful for researchers and practitioners in the maritime field who have not yet established cooperation with IMHA and its members. Further promotion of this development is therefore recommended and it is suggested that we should all use our networks to do so.

The IMHA website (http://www.imha.net/) provides links to resources that can promote research and collaboration, e.g. the web-based Textbook of Maritime Medicine and IMHA Research Group (http://www.imha.net/latest-news/ imharg.html), which is prepared to provide multifarious types of assistance to the current IMHA members as well as new-coming members (http://www.semm.org/IMHAResearch/IMHAResearchMandateOct2014tc-amh.pdf). IMHA Research was presented at the $12^{\text {th }}$ ISMH in Brest in 2013 and subsequently approved by the IMHA Board. In February 2014, IMHA Research Group was included in the IMHA Strategy Meeting in London, and the first General Meeting and Workshop of IMHA Research was held in Barcelona 


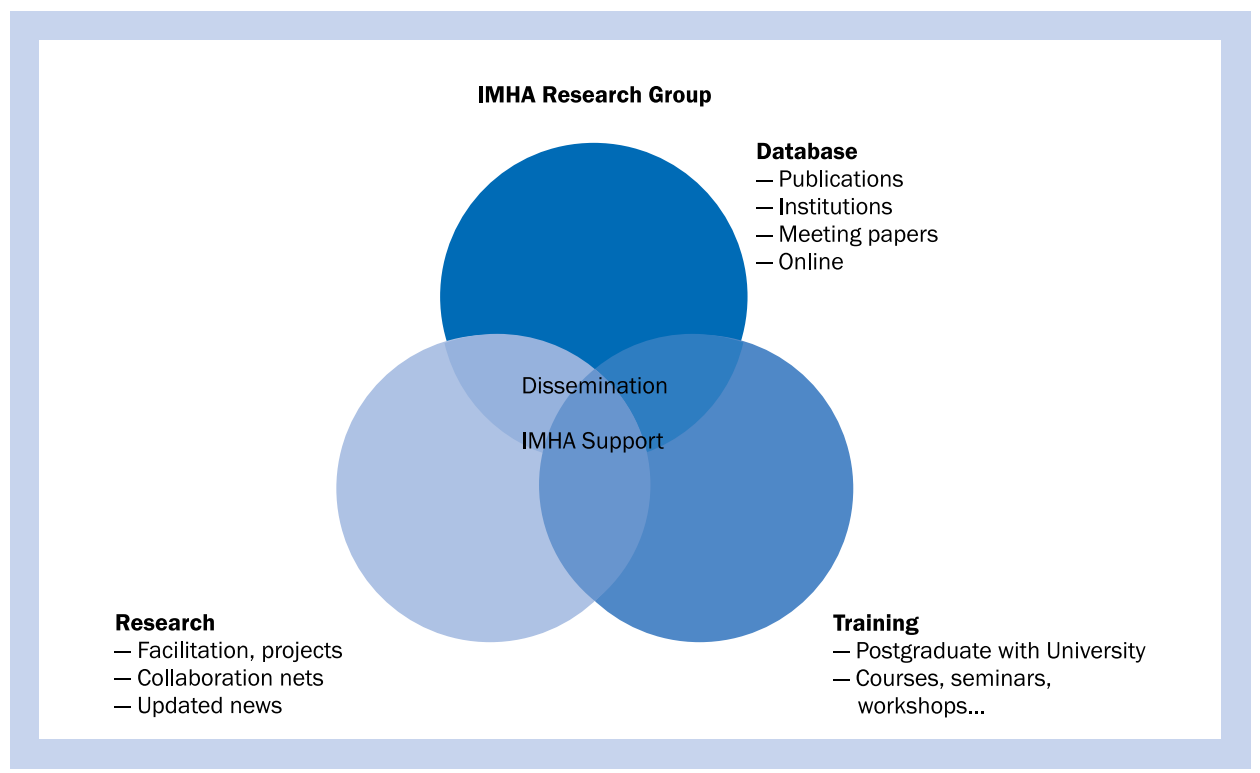

Figure 1. Scope of International Maritime Health Association (IMHA) Research Group; Source: Canals ML, Jensen OC. IMHA Research Group Report, 2015

in October 2014. Since then several meetings have taken place and the scope of IMHA research has been further developed [2]. IMHA Research Group will develop databases on publications, researchers, institutions, scientific societies and ongoing projects in the field of maritime health and safety (Fig. 1). In addition, IMHA Research Group aims to provide support with regard to the conduction of research and to research methodology as well as to language editing.

This correspondence proposes that IMHA and IMHA members follows the interdisciplinary path, which is already the trend seen in the ISMH symposia and in the 'International Maritime Health' journal, and pursues further development towards an increased global coverage in the field of maritime health and safety research. Active marketing of IMHA should aim to attract even more members and approach potential newcomers at a global scale by offering them all the services and support that IMHA and IMHA Research can offer, and by promoting the cooperation, mutual inspiration, and friendship of every IMHA member to newcomers. The option of corporate membership should be emphasized to expand our coverage.
We suggest that IMHA and IMHA members should look around for all potential stakeholders in the field and invite them to participate in the IMHA activities.

\section{REFERENCES}

1. MacLachlan M, Kavanagh B, Kay A. Maritime health: a review with suggestions for research. Int Marit Health 2012; 63: 1-6.

2. Canals ML. IMHA Research: Why? How? Who? IMHA Newsletter 2015; 14: 17-18.

3. Carter T. Mapping the knowledge base for maritime health: 3 illness and injury in seafarers. Int Marit Health 2011; 62: 224-240.

4. Canals ML, Nogueroles PJ, Rodríguez F, Fenoll MR, Jegaden D, Rodríguez MM. International Postgraduate Courses in Maritime medicine, a challenge to joint universities. Arch Mal Prof Enviro 2013; 74: 575.

5. McCarthy N, O'Flynn S, Murphy J, Barry D, Canals ML. Evaluation of the educational impact of a special study module on maritime medicine for medical undergraduate students. Int Marit Health 2013; 64: 195-201.

6. Fenoll-Brunet MR, Canals ML, Nogueroles PJ, Jensen OC, Herrador $J$, Jégaden D. Maritime health international e-learning postgraduate medical education courses: An inter-university collaboration to train health professionals around the world. AMEE 2015; 4-9 September, Glasgow, 2015. 